\title{
Loss of Feedback Information Given during Oral Presentations
}

\author{
ACHIM ELFERING \\ University of Bern, Switzerland, \\ and National Centre of Competence in Research, Affective Sciences, \\ University of Geneva, CISA, Geneva, Switzerland \\ SIMONE GREBNER \\ Central Michigan University, USA \\ SILKE WEHR \\ University of Bern, Switzerland
}

\begin{abstract}
Oral presentation of a research proposal for a Master's thesis can be stressful for psychology students. During and after the presentation, students often miss or forget feedback to their research proposal. The study tested whether information loss after receiving feedback depended upon the amount of supervisor feedback, the retention time, and experience in giving Master's thesis research proposal presentations. Students had to present a research proposal three times and feedback was recorded by a record clerk. After each presentation students were obliged to send their remembered feedback to their supervisors. Forty-three Master's students gave 101 presentations of their Master's thesis research proposal to their supervisors and colleagues. On average $40 \%$ of the supervisor feedback information was missed by students. Retention time, measured as the time between presentation and arrival of the student mail recording the remembered feedback, and the amount of supervisor feedback were positively related to loss of information. A significant interaction between the amount of supervisor feedback and retention time indicated that loss of information was immediate when supervisor feedback was extensive, while information loss was comparably low and increased moderately with retention time when supervisor feedback was brief. In stressful oral presentations recording of supervisor feedback is highly recommended.
\end{abstract}

Coherent oral presentation of complex matters is often required in academic settings and in occupational life, but students often fail to perform well in giving presentations because of a lack of presentation training as part of university curricula (Mitchell \& Bakewell, 1995). Employers and educational experts widely agree that oral presentation will become ever more important over time and that higher education should provide more training in this area (Morgan, 1997; Pribyl, Keaten, \& Sakamoto, 2001). Expert feedback on oral presentation compared to other forms of feedback boosts learning, not only in academic contexts (De Grez, Valcke, \& Roozen, 2009a). Consequently, many students at various educational levels have to present orally to peers and instructors and get feedback on their presentation (Hancock, Stone, Brundage, \& Zeigler, 2010). For instance, the Association of American Medical Colleges recommend expert feedback on oral presentation of medical history within medical student education (Association of American Medical Colleges, 2004). Nevertheless, the learning processes arising from expert feedback have been rarely investigated (Campbell, Mothersbaugh, Brammer, \& Taylor, 2001).

So far studies that address the development of instruments to evaluate oral presentations (Conor, 2006) include comparisons of evaluation instruments (Carlson \& Smith-Howell, 1995). 
Other studies have investigated the agreement between self- and peer-assessment of oral presentation skills (Campbell et al., 2001; Cheng \& Warren, 2005; Langan et al., 2005). Further research studies have focused on what presentation skills should comprise (e.g., Andeweg \& de Jong, 1998) or how to deal best with public speaking anxiety (e.g., Behnke \& Sawyer, 2000). Some studies investigate the role of student characteristics such as socioeconomic background in an elite university (Johnson, Richeson, \& Finkel, 2011), and self-efficacy in self-regulated learning as an outcome (Johnson et al., 2011), antecedent and moderator of learning (e.g., Adams, 2004).

The few studies that focus on learning processes have addressed the learning of oral presentation skills and tested the impact of the optimal number of oral presentations (Calcich \& Weilbaker, 1992), placement of presenters, time intervals between presentations and issues of preparing to present (Bayless, 2004). So far, a very small number of studies have focused on the feedback process within training (e.g., de Grez et al., 2009a) as a means of understanding the learning of oral presentation skills.

De Grez et al. (2009a, 2009b) tested the differential effect of three sources of feedback on oral presentation performance. Students did three oral presentations. After the first presentation was done without any instructions students were shown a standardised instructional videotape before their second presentation. Performance significantly improved from the first to the second presentation. After the second presentation students were randomly assigned to three sources of feedback: expert, or video-based self-evaluation. Again, performance improved from the second to the third presentation. The improvement in performance was highest after expert feedback (13\%), and lower after peer feedback (7.5\%) and self-evaluation (0.2\%).

The results of de Grez et al. (2009a, 2009b) and earlier work (Bourhis \& Allen, 1998) show that expert oral feedback on oral presentation is highly effective. However, given the current trend in higher education is to reduce in-class instruction time (De Grez et al., 2009b) it is important that expert feedback, as a valuable but scarce resource, should be as efficient as possible.

The present study focuses on student memory for expert feedback during and after oral presentation of their Master's thesis' research proposal. Feedback to students is defined as 'information describing students' performance in a given activity that is intended to guide their future performance in [the] same or in a related activity' (Ende, 1983, p. 777). Students should understand and internalise feedback in order to take an active role in feedback processes (Nicol \& Macfarlane-Dick, 2006). In this study, students present their Master's thesis research proposal three times to their supervisors. Time between presentations is four weeks. The goal is to develop their proposal that usually starts with rather broad unfocused ideas towards precise focused hypotheses. Supervisor feedback is essential for this process to progress. Unfortunately, during the oral presentation of the derivation of and rationale for their Master's thesis research proposal, students are highly aroused (Gilkinson, 1942) and within this stressful situation often they do not understand or remember feedback information very well. Therefore, we expected high loss of the supervisor feedback information that was given during and immediately after the oral presentation (Hypothesis 1). The loss of information would be apparent when students' reports of remembered feedback were compared to a record of feedback points that were taken down during and after the presentation by a recording clerk.

Loss of supervisor feedback information should depend on storage and most models of memory assume multiple stores. As part of the information processing system, the sensory store for a short time passively saves detailed images of information that reaches the sensory organs. The short-term store takes in only a small part - and too much feedback from supervisors will lead to immediate loss at this stage - for further processing. In the short-term store, information can be preserved for a couple of seconds, whereupon the processing and interpretation of stimuli is enabled (Balsam, 1985). The goal of instructors in training of oral presentation is to anchor the feedback in the long-term store of the student (Balsam, 1985). Thus, expert feedback should avoid information overload. We expected loss of information to depend on memory load - i.e., the quantity of feedback given by experts (Hypothesis 2).

With increasing retention time in working memory there is both decay of memory traces and increase of interference with previous and subsequent information (Baddeley, 1986). Thus with increasing time until students make their notes on remembered feedback, loss of information is expected to increase (Hypothesis 3). 
Finally, memory load and retention time were expected to interact. If the number of points in the feedback was low; i.e., lower than or in the range of memory capacity of $7 \pm 2$ points that can enter short-term memory and reach long-term storage (Miller, 1956), retention would be complete irrespective of retention time (Hypothesis 4). Loss of information would increase with retention time when the number of points in the feedback was greater than nine points. To investigate this hypothesis we tested the interaction between amount of feedback and retention time.

\section{Cognitive Processing during Stressful Presentations}

One might assume graduate students to be capable of storing more feedback information than the range of memory capacity of $7 \pm 2$ points because they are familiar with the content of feedback. However, anticipation of public speech and public speaking elicits stress in most individuals (Gilkinson, 1942). Many standardised stress tests therefore include anticipation of public speech or public speaking (e.g., Boucsein \& Wendt-Suhl, 1981; Kirschbaum, Pirke, \& Hellhammer, 1993). Anticipation of public speaking and public speaking induce ego-threat and a shift of attention focus towards the self (Kallus, 1992). Thus, cognitive information processing is rather limited during stressful public speaking. Most attention is directed towards self-monitoring and there is nearly no capacity left for secondary tasks such as context-based chunking of comments made by the audience.

So far, empirical evidence on habituation with public speaking stressors stems from studies that have investigated habituation to repeated exposure of the Trier Social Stress Test (TSST), which includes a speaking task and mental arithmetic in front of an audience (Kirschbaum, 2010; Kirschbaum et al., 1995). Consistent evidence shows habituation of the cortisol stress response, however, decline upon the second TSST exposure within one week (Kirschbaum et al., 1995). Students in our study are expected to habituate to oral presentation stress as they proceed from their first to third presentation.

It is well established that stress increases avoidance of negative or threatening information (Ellenbogen, Schwartzman, Stewart, \& Walker, 2002). However, very few studies so far have investigated feedback-based learning (also named reward-based learning) after public speaking stress. Most recently, Petzold, Plessow, Goschke, and Kirschbaum (2010) induced stress by administering the TSST and afterwards participants did attend significantly less to negative feedback than after participating in the control condition that included only reading of magazines. With respect to processes involved, Petzold et al. (2010) argued that stress-induced elevated levels of cortisol enhanced dopamine output within the central nervous system reward circuit, that reduces attention to negative feedback. Thus, in the present study we expected attention to negative feedback to be inversely related with habituation to oral presentation. With habituation to repeated presentations - i.e., from the first presentation to the second and third presentation to the same audience - attention to feedback should increase and loss of feedback information should be lower in the second presentation compared to the first presentation and in the third presentation compared to the second presentation (Hypothesis 5).

\section{Hypotheses}

In this study students were expected to miss many feedback points their supervisors made about their presentation. The comparison of student emails recording their remembered supervisor feedback with the records of feedback points that were taken down during and after the presentation by a recording clerk were expected to show that:

1. Students would fail to remember feedback points that were made during and after their presentation;

2. The proportion of feedback information loss would be positively associated with the number of supervisor feedback points;

3. The proportion of feedback information loss would be positively associated with the delay in students' writing the email with their remembered feedback points to the supervisor;

4. If the number of feedback points is in the range of memory capacity of $7 \pm 2$ points that can enter long-term storage (Miller, 1956), no loss of feedback information is expected irrespective 
of the delay in writing the email. However, loss of feedback information is expected to increase with retention time when the number of points in the feedback is greater than nine points;

5. Loss of feedback information decreases with experience of oral presentation of the Master's proposal. After the third presentation feedback information loss is smaller than after the second presentation and the loss after the second presentation is smaller than after the first presentation.

\section{Method}

Design

The field study investigated students who were starting their Master's thesis in work and organisational psychology. In the seminar students had to develop their research questions and hypotheses and present their Master's thesis research proposal three times to the audience of other Master's course participants and their supervising teaching staff. Courses were intensive and took place on Saturday mornings and afternoons. There were five to eight students participating in each course, and six courses were followed across three years.

\section{Participants}

All participants in the six seminars - i.e., 43 psychology Master's students (29 women and 14 men, mean age $=28.1$ years, $S D=2.3$ years $)-$ volunteered to participate. The feedback recording procedure was an integral part of the course content. All participants agreed to the evaluation of remembered feedback by supervisors and were informed that they must send their remembered feedback to the teachers of the seminar first, before they would receive the record of feedback that was recorded during their presentation. Informed consent was obtained from all participants. The study was performed in accord with all the requirements defined by the Swiss Society of Psychology.

\section{Procedure}

Starting at 9 am on a Saturday, participants presented their Master's thesis research proposal by giving a PowerPoint presentation in front of an audience of other participants and two of the department's supervisors (the first and second author). During the presentation of their Master's thesis research proposals the supervisors gave comments and made suggestions. Students were also instructed to ask their supervisors for advice and students were free to take notes during their presentation. Presentations on average took 30 minutes. A research assistant served as a record clerk and made a record of ongoing comments, suggestions, and references made by the supervisors. After the presentation, the supervisors looked at the record to check that it was complete and correct.

At the end of the seminar day students were instructed to send an email to their supervisors covering all the points they remembered from the feedback they had received during and following their presentation (instructions for full recall). The instruction did not ask the students to send the feedback as quickly as possible ('Please do not forget to send the feedback you remember by email'). The students had no prior experience of presenting their Master's thesis research proposal to an audience of colleagues and supervisors when the course started.

\section{Scoring}

Retention time. The time between the end of the course on Saturday and the arrival of the student email was calculated as number of hours elapsed and served as indicator of the retention time.

Feedback content and loss in feedback information. Master's students had the goal to present and justify their hypotheses derived from their research question. Most feedback points from supervisors therefore addressed the following criteria for hypotheses: 
(1) Were the hypotheses clearly linked to the research question?

(2) Were the hypotheses consistent (without inherent contradiction)?

(3) Were the hypotheses formulated on a concrete construct level (operationalisation)?

(4) Were the hypotheses as specific as possible (e.g., directional where appropriate and not nondirectional where not appropriate)?

(5) Did the hypotheses correctly include only one assumption (no mix of assumptions like 'men make fewer errors and perform quicker than women')?

(6) Did the hypotheses correctly state what was intended with respect to processes (e.g., a hypothesis describing a moderation effect where a mediation effect was intended to be described)?

The number of supervisor feedback points was extracted from the record clerk's feedback protocol, and the number of feedback points remembered by the students was extracted from the students' emails. Both procedures were highly reliable, as a comparison of two raters showed an ICC $=.89$ for both procedures. The dependent variable was percentage of feedback points lost. Percentage of feedback points lost was calculated as the difference between the number of feedback points recorded by the record clerk's feedback protocol and the number of feedback points remembered by the students in their emails.

\section{Data Analysis}

The data contain information at individual subject level and at the situation level of the presentations, with presentations nested within persons. This leads to a number of statistical problems. On the one hand, a simple aggregation of trial-related information at the person level would lead to a loss of information and statistical power. On the other hand, analyses on the situation level (disaggregated data) would lead to a 'blown up' data set with respect to the higherlevel units (persons), and spurious significances may result (see Hox, 2002). To deal with this problem, a multilevel regression analysis was employed that allows for testing the influence of situation-related variables and person-related measures. The dependent variable in multilevel regression analysis was percentage of feedback points lost.

Given that 43 participants could make three presentations, the maximum sample size in multilevel regression analysis was 129 . There was, however, a loss of 10 presentations across eight of the students who did not attend one or two course days because of illness. Another 18 presentations by 14 students did receive supervisor feedback but the students failed to email their number of feedback points remembered to the tutor. Therefore, the final sample size was 101 . The sample sizes in multilevel regression analysis on the person level (level 2, $n=43$ ) and presentation level (level 1, $n=101$ ) were sufficient (Maas \& Hox, 2005). The sample size of level 2 was a little lower than the recommended size $(n=50)$ but given that no level 2 predictor variables were included in the model, and that hypotheses addressed no crosslevel interactions, the estimates of the regression coefficients, the variance components, and the standard errors were likely to be accurate (Maas \& Hox, 2005). Multilevel regression analyses were done with MLwiN software version 1.10 (Rasbash et al., 2000). Alpha was set to .05, two-tailed.

\section{Results}

Table 1 shows descriptive results and correlations between study variables for the three repeated presentations. Correlations between feedback loss and memory load were significant only for the first presentation but not the second or third presentations. Correlations between feedback loss and retention time were not significant for the first and third presentations but reached significance level for the second presentation.

The supervisors provided many comments, suggestions and pieces of advice to the students during their Master's thesis presentations. On average, the record clerks listed 21.5 feedback points during each presentation $(S D=12.3)$. From the students' emails listing the feedback points they remembered, it became clear that they had missed many issues. The mean number of points listed by students was $10.8(S D=6.4)$. These numbers therefore confirmed a huge loss of information (Hypothesis 1). Mean information loss, expressed as the difference between the record clerk's 
protocol of feedback points and feedback points listed in students' email was $8.9(S D=6.0)$. On average, $44.2 \%$ of information was lost $(S D=21.1 \%)$. A one-sample $t$ test showed that percentage of information loss differed significantly from zero $(t(100)=21.05, p<.001)$.

Table 1. Means, Standard Deviations and Correlations between Study Variables

\begin{tabular}{|c|c|c|c|c|c|c|c|c|c|c|c|}
\hline & Mean & $S D$ & $n$ & $\begin{array}{c}\text { FB loss } \\
\text { t1 (\%) }\end{array}$ & $\begin{array}{l}\text { FB loss } \\
\text { t2 (\%) }\end{array}$ & $\begin{array}{c}\text { FB loss } \\
\text { t3 (\%) }\end{array}$ & $\begin{array}{c}\text { \# FB } \\
\text { points } \\
\mathrm{t} 1\end{array}$ & $\begin{array}{c}\text { \# FB } \\
\text { points } \\
\text { t2 }\end{array}$ & $\begin{array}{c}\text { \# FB } \\
\text { points } \\
\text { t3 }\end{array}$ & $\begin{array}{l}\text { Retention } \\
\text { time } \mathrm{t} 1\end{array}$ & $\begin{array}{c}\text { Retention } \\
\text { time } \mathrm{t} 2\end{array}$ \\
\hline $\begin{array}{l}\text { FB loss } \mathrm{t} 1 \\
(\%)\end{array}$ & 45.67 & 20.06 & 37 & & & & & & & & \\
\hline $\begin{array}{l}\text { FB loss } \mathrm{t} 2 \\
(\%)\end{array}$ & 38.90 & 23.10 & 35 & .28 & & & & & & & \\
\hline $\begin{array}{l}\text { FB loss } \mathrm{t} 3 \\
(\%)\end{array}$ & 48.69 & 19.13 & 29 & $.52^{\star \star}$ & $.52^{\star \star}$ & & & & & & \\
\hline $\begin{array}{l}\text { \# FB } \\
\text { points t1 }\end{array}$ & 18.66 & 8.98 & 41 & $.38^{\star}$ & -.32 & .22 & & & & & \\
\hline $\begin{array}{l}\text { \# FB } \\
\text { points t2 }\end{array}$ & 20.26 & 7.38 & 38 & -.16 & .15 & .15 & -.02 & & & & \\
\hline $\begin{array}{l}\text { \# FB } \\
\text { points t3 }\end{array}$ & 25.55 & 17.22 & 40 & .04 & -.29 & .31 & $.56^{\star \star \star}$ & .00 & & & \\
\hline $\begin{array}{l}\text { Retention } \\
\text { time } t 1\end{array}$ & 1.72 & 0.41 & 37 & .20 & $.49^{\star \star}$ & $.39^{\star}$ & -.06 & -.14 & -.14 & & \\
\hline $\begin{array}{l}\text { Retention } \\
\text { time t } 2\end{array}$ & 1.82 & 0.45 & 35 & -.16 & $.40^{\star}$ & .19 & -.32 & .11 & -.13 & .34 & \\
\hline $\begin{array}{l}\text { Retention } \\
\text { time } \mathrm{t} 3\end{array}$ & 1.86 & 0.43 & 29 & .28 & .13 & .09 & .27 & .22 & -.08 & -.06 & -.02 \\
\hline
\end{tabular}

Note. $\mathrm{t} 1, \mathrm{t} 2, \mathrm{t} 3$ = first, second, third oral presentation of Master's thesis research proposal; FB loss = loss of feedback information; \# FB points = number of supervisor feedback points; retention time $=$ delay in students' reply to the supervisor with remembered feedback points $[\log 10$ hours $] .{ }^{\star} p<.05,{ }^{\star \star} p<.01,{ }^{\star \star \star} p<.001$, two-sided.

Table 2. Multilevel regression analysis predicting loss of feedback information.

\begin{tabular}{lcc}
\hline Predictor variables & & \\
\hline Intraclass correlation & \multicolumn{2}{c}{0.36} \\
Fixed effects & Param & SE \\
Intercept & -19.03 & 19.02 \\
Level 1 (presentation) & & \\
First, second, and third presentation of Master's thesis concept & 0.25 & 1.97 \\
Number of supervisor feedback points & $2.71^{\star \star}$ & 0.95 \\
Retention time [log10 hours] & $31.50^{\star \star}$ & 10.52 \\
Level 1 interactions & & \\
Number of supervisor feedback points x retention time & $-1.33^{\star}$ & 0.53 \\
Random effects & & \\
VAR level 2 & $174.15^{\star \star}$ & 62.27 \\
VAR level 1 & $232.56^{\star \star \star}$ & 41.75 \\
$2^{\star}$ log likelihood (IGLS) & 878.53 & \\
AIC & 886.53 & \\
\hline
\end{tabular}

Note. Sample size is $N=101$ deviations between student replies giving remembered feedback points and record clerks' records, reported by 43 participants. Param. = fixed parameter estimates; $S E=$ standard error; IGLS = Iterative Generalized Least Squares; AIC = Aikaike information criterion, a fit measure of model parsimony. Random effects = variance and covariance estimates of parameters that are allowed to vary on level 2.

${ }^{\star} p<.05,{ }^{\star \star} p<.01,{ }^{\star \star \star} p<.001$, two-sided. The Wald test is one-sided for variances (VAR). 
Multilevel regression analysis considered the dependency of the data structure, and the variance components model showed an intraclass correlation coefficient (ICC) of .36, as shown in Table 2. The total variation in information loss split into both levels of data, i.e. person-bound characteristics (36\% of variation) and characteristics of the presentation (64\% of variation). Thus the data levels were dependent and multilevel regression analysis was appropriate.

When predictor variables were included into the multilevel regression model, quantity of supervisor feedback (Hypothesis 2 : $\mathrm{B}=2.71, \mathrm{SE}=0.95, p<.01$ ) and retention time (Hypothesis 3 : $\mathrm{B}=31.50, \mathrm{SE}=10.52, p<.01)$ were significant predictors of information loss.

A significant interaction between quantity of supervisor feedback and retention time predictor variables showed that the expected increase in loss of information with retention time was observed when supervisor feedback was one standard deviation $(S D=12.30)$ or greater below the mean of 21.50 - i.e., supervisor feedback did not exceed 10 points. If the supervisor feedback was rather extensive (i.e., one standard deviation or more above the mean), most information was immediately lost and there was no further increase of information loss with longer retention times (Hypothesis 4, compare Figure 1). There was no significant decrease of information loss from first to second and third presentation, as proposed in Hypothesis $5(\mathrm{~B}=0.25, \mathrm{SE}=1.97, n s)$.

Figure 1. Percentage loss of feedback information regressed on amount of supervisor feedback and retention time.

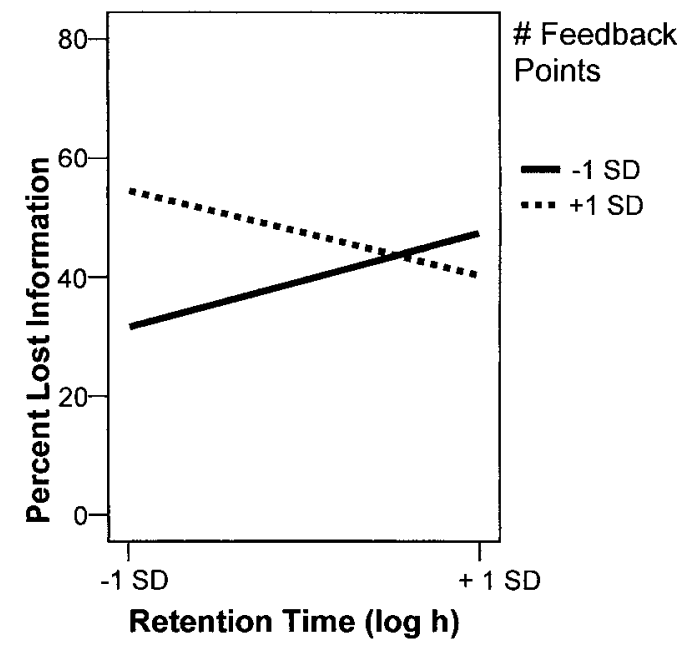

\section{Discussion}

So far, to our knowledge, only a few studies have investigated supervisor feedback on oral presentation (de Grez et al., 2009a, 2009b). In this study students had to remember supervisor feedback and email their notes to supervisors before they received the record clerk's feedback protocol. Results showed extensive loss of feedback information. Meanwhile the loss of feedback points is likely to be underestimated in this study compared to the standard procedure where students do not have to write an email with their remembered feedback. In making the notes students reported they memorised points they otherwise would have forgotten. Noteworthy, in evaluation of the course, students valued the notes as useful in self-regulated learning (cf. de Grez et al., 2009b). Beside students forgetting many feedback points in this study, supervisors also noticed from students' emails that students often did not understand feedback points as intended. Indeed, as a consequence of this investigation we kept student feedback emails in our courses. Student emails with remembered feedback helped to increase the convergence of student and supervisor perspectives and contributed to what is called a powerful learning environment (Könings, Brand-Gruwel, \& van Merriënboer, 2005). Future studies should investigate students' misconceptions in remembered feedback in more detail. For instance, Haber and Lingard (2001) 
did a qualitative analysis of oral presentations and teacher comments. Often teacher feedback was misunderstood and resulted in worse student communications skills (e.g., the comment 'be brief resulted only in speeding up the talk).

When Master's students get accustomed to oral presentations some adaptation to the stressor of public speaking should occur (McEwen, 1998), consisting of cognitive processing changes away from basic heuristics and attention that is more focused on the self, towards attention to inputs from others (Semmer, Grath, \& Beehr, 2005). Forgetting of feedback information should decrease with increased presentation experience. In this study, we did not confirm that hypothesis. However, a major limitation of the study is that we did not differentiate between valence of the feedback. Petzold et al. (2010) found memory for negative feedback after oral presentation to be less good than memory for neutral or positive feedback.

Finally, the study confirmed the limited memory capacity of individuals by showing that the loss of feedback information is strongly predicted by the amount of feedback given. It is, of course, true that feedback should be as concise as possible, to fit the memory capacity of $7 \pm 2$ items (Miller, 1956). In higher education, however, when Master's students present their developing work this is unrealistic. Indeed, feedback to presentations often included more points (median $=19$ ) as it addressed the introduction, theory, models, hypotheses, and methods of a Master's thesis project. In this situation, logfile records made by others during presentations and student feedback of remembered feedback points seem to be useful. From our results it appears adequate for supervisors to receive students' emails with remembered feedback points first and send the logfile records to students afterwards. This procedure should help to intensify students' reflections about their own presentation performance. However, we agree with de Grez et al. (2009a) that further studies are necessary that investigate the pacing and timing of feedback in training of oral presentations. Future studies also should differentiate the nature of feedback - i.e., outcome-related feedback, and process- and calibration-related feedback (de Grez et al., 2009a).

\section{Limitations}

The study is only observational, not experimental, and as mentioned previously did not differentiate between the effects of negative and positive feedback. Though considerable efforts were made to make the presentation setting comparable to all students, it proved difficult to completely standardise the situation due to the authentic character of the environment. This implies that a number of variables could not be controlled for in the present study. It was, for example, not possible to control for student performance motivation that may influence both remembered feedback and point in time of writing the corresponding email.

The natural setting of the study also accounts for the small sample size that is another limitation. Because of the very intense course format the number of participants is rather limited. Furthermore, the study does not include a control group - for example, students getting feedback on a printout of their representation - to show the reported loss of feedback information is especially high in oral presentations. Recording of the feedback during the presentation in a logfile by a recording clerk does not rule out that recording clerks missed some information. Recording clerks, however, were experienced in their task and were instructed to inquire immediately when they did not understand feedback from supervisors.

Another limitation is that students' delay in writing the email with remembered feedback points is only a rough estimate of real time of delay in recall. The processes behind information loss with delay in writing the email containing remembered feedback points may involve delay in recall, interference effects, and even procrastination in sending off the email. Indeed, the information loss may involve various memory processes: information may not be encoded, be decayed during retention, or incorrectly reported in remembering.

Further studies should also test whether the mere quantity but also the quality (importance and salience) of supervisor feedback might have influenced feedback recall. This field study therefore lacks clarity with respect to processes involved in loss of feedback information. Nevertheless, the study results are of practical relevance in teaching psychology. To some degree, the results are relevant for teaching in other disciplines, too. 


\section{Conclusions}

In learning psychology at university level, most students have to present their Master's thesis research proposal to an experienced academic audience. Supervisors should be aware that in this stressful situation most students are unable to attend to and to remember many suggestions. Information loss is huge. Logfile recording and closed-loop communication of feedback are highly recommended. If closed-loop communication of feedback is impossible due to various constraints, supervisor feedback should be concise and restricted to the most important points.

\section{References}

Adams, K. (2004). Modelling success: Enhancing international postgraduate research students' self-efficacy for research seminar presentations. Higher Education Research and Development, 23, 115-130.

Andeweg, B., \& de Jong, J. (1998). 'May I have your attention?’: Exordial techniques in informative oral presentations. Technical Communication Quarterly, 7, 271-284. http: / / dx.doi.org/10.1080/10572259809364631

Association of American Medical Colleges. (2004). Medical School Objectives Project (MSOP) - Initiatives AAMC. Retrieved February 10, 2011, from https://www.aamc.org/initiatives/msop/

Baddeley, A. D. (1986). Working memory. Oxford: Oxford University Press.

Balsam, P. D. (1985). The functions of context in learning and performance. In P. D. Balsam \& A. Tomie (Eds.), Context and learning (pp. 1-22). New Jersey: LEA.

Bayless, M. (2004). Change the placement, the pace, and the preparation for the oral presentation. Business Communication Quarterly, 67, 222-225. http:/ / dx.doi.org/10.1177/1080569904672011

Behnke, R., \& Sawyer, C. (2000). Anticipatory anxiety patterns for male and female public speakers. Communication Education, 49, 187-195. http:/ / dx.doi.org/10.1080/03634520009379205

Boucsein, W., \& Wendt-Suhl, G. (1981). An experimental investigation of elements involved in the anticipation of public speaking. Archiv für Psychologie, 133, 1-8.

Bourhis, J., \& Allen, M. (1998). The role of videotaped feedback in the instruction of public speaking: A quantitative synthesis of published empirical research. Communication Research Reports, 15, 256-261. http: / / dx.doi.org/10.1080/08824099809362121

Calcich, S., \& Weilbaker, D. (1992). Selecting the optimum number of in-class sales presentations. Marketing Education Review, 2, 31-33.

Campbell, K., Mothersbaugh, D., Brammer, C., \& Taylor, T. (2001). Peer versus self assessment of oral business presentation performance. Business Communication Quarterly, 64, 23-42. http: / / dx.doi.org/10.1177/108056990106400303

Carlson, R., \& Smith-Howell, D. (1995). Classroom public speaking assessment: Reliability and validity of selected evaluation instruments. Communication Education, 44, 87-97. http: / / dx.doi.org/10.1080/03634529509379001

Cheng, W., \& Warren, M. (2005). Peer assessment of language proficiency. Language Testing, 22, 93-121. http: / / dx.doi.org/10.1191/0265532205lt298oa

Conor, C. (2006). Enhancing reflective learning through role-plays: The use of an effective sales presentation evaluation form in student role-plays. Marketing Education Review, 16, 9-13.

De Grez, L., Valcke, M., \& Roozen, I. (2009a). The impact of goal orientation, self-reflection and personal characteristics on the acquisition of oral presentation skills. European Journal of Psychology of Education, 24, 293-306. http: / / dx.doi.org/10.1007/BF03174762

De Grez, L., Valcke, M., \& Roozen, I. (2009b). The impact of an innovative instructional intervention on the acquisition of oral presentation skills in higher education. Computers and Education, 53, 112-120. http: / / dx.doi.org/10.1016/j.compedu.2009.01.005

Ellenbogen, M. A., Schwartzman, A. E., Stewart, J., \& Walker, C. (2002). Stress and selective attention: The interplay of mood, cortisol levels, and emotional information processing. Psychophysiology, 39, 723-732. http: / / dx.doi.org/10.1111/1469-8986.3960723

Ende, J. (1983). Feedback in clinical medical education. Journal of the American Medical Association, 250, 777-781. http: / / dx.doi.org/10.1001/jama.1983.03340060055026

Gilkinson, H. (1942). Social fears as reported by students in college speech classes. Speech Monographs, 9 , 141-160. http:/ / dx.doi.org/10.1080/03637754209390068 
Haber, R. J., \& Lingard, L. A. (2001). Learning oral presentation skills: A rhetorical analysis with pedagogical and professional implications. Journal of General Internal Medicine, 16, 308-314. http:/ / dx.doi.org/10.1046/j.1525-1497.2001.00233.x

Hancock, A. B., Stone, M. D., Brundage, S. B., \& Zeigler, M. T. (2010). Public speaking attitudes: Does curriculum make a difference? Journal of Voice, 24, 302-307. http: / / dx.doi.org/10.1016/j.jvoice.2008.09.007

Hox, J. J. (2002). Multilevel analysis. Mahwah, NJ: Lawrence Erlbaum.

Johnson, S. E., Richeson, J. A., \& Finkel, E. J. (2011). Middle class and marginal? Socioeconomic status, stigma, and self-regulation at an elite university. Journal of Personality and Social Psychology, 100, 838-852. http: / / dx.doi.org/10.1037/a0021956

Kallus, K. (1992). Beanspruchung und Ausgangszustand [Stress and initial state]. In D. Frey, H. Keupp, E. D. Lantermann, R. K. Silbereisen, \& B. Weidenmann (Eds.), Fortschritte der psychologischen Forschung, Bd. 14. Weinheim: Beltz.

Kirschbaum, C. (2010). TSST. In I. P. Stolerman (Ed.), Encyclopedia of psychopharmacology (pp. 1344-1346). Berlin: Springer-Verlag.

Kirschbaum, C., Pirke, K. -M., \& Hellhammer, D. H. (1993). The 'Trier Social Stress Test' - A tool for investigating psychobiological stress responses in a laboratory setting. Neuropsychobiology, 28, 76-81.

Kirschbaum, C., Pruessner, J. C., Stone, A. A., Federenko, I., Gaab, J., Lintz, D., ... Hellhammer, D. H. (1995). Persistent high cortisol responses to repeated psychological stress in a subpopulation of healthy men. Psychosomatic Medicine, 57, 468-474. http:/ / dx.doi.org/10.1159/000119004

Könings, K., Brand-Gruwel, S., \& van Merriënboer, J. (2005). Towards more powerful learning environments through combining the perspectives of designers, teachers, and students. British Journal of Educational Psychology, 75, 645-660. http:/ / dx.doi.org/10.1348/000709905X43616

Langan, A., Wheater, C., Shaw, E., Haines, B., Cullen, W., Boyle, J., .... Preziosi, R. (2005). Peer assessment of oral presentations: Effects of student gender, university affiliation and participation in the development of assessment criteria. Assessment and Evaluation in Higher Education, 30, 21-34. http:/ / dx.doi.org/10.1080/0260293042003243878

Maas, C. J., \& Hox, J. J. (2005). Sufficient sample sizes for multilevel modeling. Methodology, 1, 86-92. http: / / dx.doi.org/10.1027/1614-2241.1.3.85

McEwen, B. (1998). Protective and damaging effects of stress mediators. New England Journal of Medicine, 338, 171-179. http:/ / dx.doi.org/10.1056/ NEJM199801153380307

Miller, G. A. (1956). The magical number seven, plus or minus two: Some limits on our capacity for processing information. Psychological Review, 63, 81-97. http:/ / dx.doi.org/10.1037/h0043158

Mitchell, V. W., \& Bakewell, C. (1995). Learning without doing - Enhancing oral presentation skills through peer-review. Management Learning, 26, 353-366.

Morgan, G. J. (1997). Communication skills required by accounting graduates: Practitioner and academic perceptions. Accounting Education, 6, 93-107. http: / / dx.doi.org/10.1080/ 096392897331514

Nicol, D. J., \& Macfarlane-Dick (2006). Formative assessment and self-regulated learning: A model and seven principles of good feedback practice. Studies in Higher Education, 31, 199-218. http: / / dx.doi.org/10.1080/03075070600572090

Petzold, A., Plessow, F., Goschke, T., \& Kirschbaum, C. (2010). Stress reduces use of negative feedback in a feedback-based learning task. Behavioral Neuroscience, 124, 248-255. http:/ / dx.doi.org/10.1037/a0018930

Pribyl, C. B., Keaten, J., \& Sakamoto, M. (2001). The effectiveness of a skill-based program in reducing public speaking anxiety. Japanese Psychological Research, 43, 148-155. http: / / dx.doi.org/10.1111/1468-5884.t01-1-00171

Rasbash, J., Browne, W., Goldstein, H., Yang, M., Plewis, I., Healy, M., ... Lewis, T. (2000). A user's guide to MLwiN. London: Multilevel Models Project, Institute of Education, University of London.

Semmer, N. K., McGrath, J. E., \& Beehr, T. A. (2005). Conceptual issues in research on stress and health. In C. L. Cooper (Ed.), Handbook of stress and health (2nd ed., pp. 1-43). New York: CRC Press.

ACHIM ELFERING is an associate professor in the Department of Work and Organizational Psychology at the University of Bern. His research interests include work safety, job stress including physiological stress responses, and occupational low back pain. This research has been 
internationally recognized by the SPINE Journal Young Investigator Research Award in 2001. His further works addressed issues of work-related outcome measurement, patient safety, job satisfaction research, and work socialization. Achim Elfering teaches work and organisational psychology at bachelor and master level and is president of a graduate school on health sciences. Correspondence: achim.elfering@psy.unibe.ch

SIMONE GREBNER has held appointments at the University of Munich, Germany and the Federal Institute of Technology, Zurich, Switzerland. She also held a research and teaching position at the University of Bern, Switzerland from 1995 until 2007 and at Central Michigan University, USA from 2007 until 2009. She joined the faculty at the School of Applied Psychology (APS), University of Applied Sciences Northwestern, Switzerland in 2009 as Professor of Applied Psychology.

SILKE WEHR is a research staff member at the University of Bern. She leads as deputy head the Postgraduate Certificate Programme in Higher Education in the Centre for Advanced Studies at the University of Bern, Switzerland. She received a Doctoral Scholarship from the German Research Foundation for the Graduate School in Cognitive Science, Hamburg, Germany and obtained her PhD at the University of Fribourg, Switzerland. 